\title{
A Bayesian Belief Network to evaluate issues in producing higher grades of sheet rubber by smallholder farmers in Kalutara district
}

\author{
J C Edirisinghe*, L G D P Kumara**, A P S Fernando**, H M L K Herath*, \\ U K Jayasinghe-Mudalige*, M S S Mendis* and L D M Nimanthika* \\ * Department of Agribusiness Management, Faculty of Agriculture and Plantation \\ Management, Wayamba University of Sri Lanka, Makandura, Gonawila (NWP) \\ ** Dept. of Agricultural Systems, Faculty of Agriculture, Rajarata University of Sri Lanka, \\ Puliyankulama, Anuradhapura
}

Received: 30 July 2014

\begin{abstract}
Meager production of higher quality sheet rubber is an issue which has implications on the smallholder's income as well as on the rubber products industry in the country. Although, this problem has been there for some time, it is increasingly becoming grave in the face of a vibrant rubber products manufacturing industry. However, no systematic study is found on this issue of production of higher grades partly because it is a smallholder's problem. We take up this issue from a policy perspective using a Bayesian Belief Network, which provide us with a visual output understood by laymen in the hope that findings would be beneficial to many. We find three key reasons for the lackluster performance in the production of sheet rubber in the highest quality: the lack of physical capital, lack of a proper grading system and lack of cleanliness in production. We discuss these issues at length.
\end{abstract}

Keywords: Bayesian Belief Network, Kalutara district, sheet rubber, smallholders

\section{Introduction}

Smallholder rubber producers in Sri Lanka sell their production as Ribbed Smoked Sheets (RSS) and/or as latex. The sale of latex does not involve any form of processing. However, the production of RSS undergoes some form of processing and is produced in 5 grades (RSS1 to RSS5). The prices fetched in the market declines in the order: RSS1 $>$ RSS2 $>\ldots . .>$ RSS5 $>$ Latex. For example, the difference between yearly average price of RSS1 and RSS5 in 2011 was Rs. 24.35 (Ministry of Plantation Industries, 2012). The variation in the difference between RSS1 and RSS5 is given in Figure 1. 


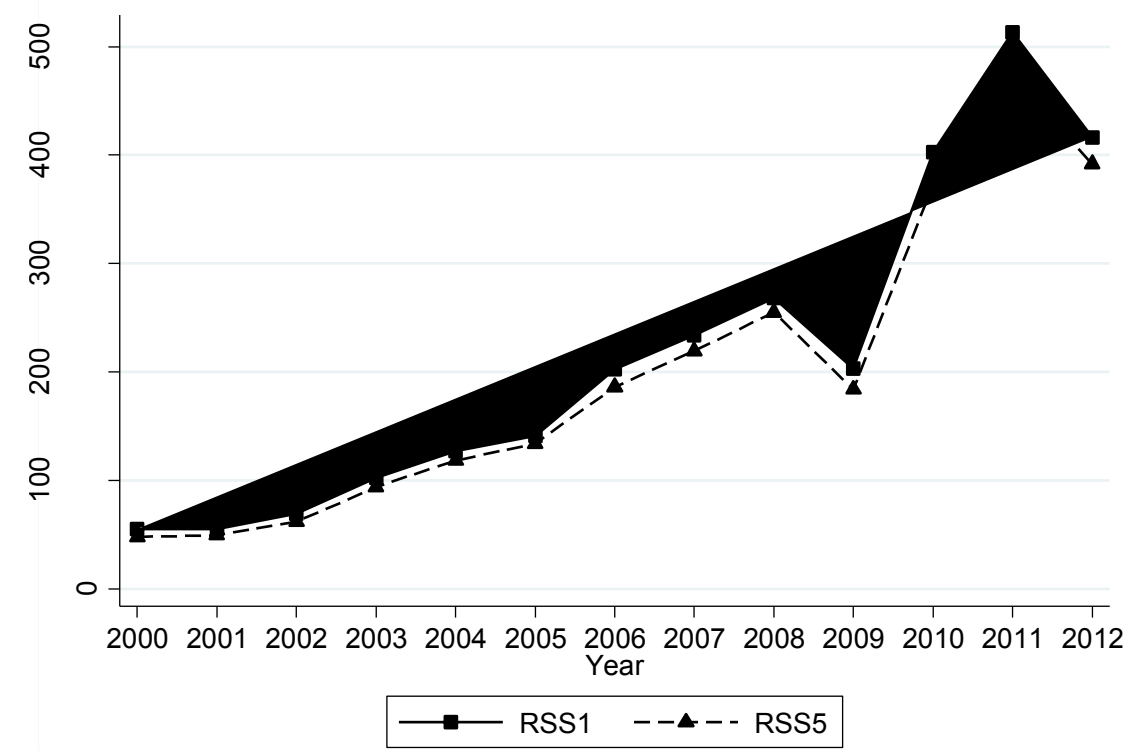

Fig. 1. Variation of RSS1 and RSS5 prices

Therefore, production of RSS 1 will increase farmer income. However, it is found that a considerable number of farmers sell as direct latex attracting the lowest prices. Additionally, farmers who produce sheet rubber do not produce the best quality grade, RSS1. Recent studies have found that majority of those who are producing sheet rubber sells their output as either RSS3 or RSS4, fetching low prices in the auction (Wijesuriya, 2008). This has two impacts on the economy. On a quality standpoint, it is important that higher quality sheet rubber be available to the rubber industry. If they are not found within the country, these have to be imported for the domestic industry, wasting valuable foreign exchange. On an income view point, this has immense impact on the farmer income as well as on the export income of the country. Therefore, it is important to assess the reasons for smallholder farmers' unwillingness/inability to produce higher quality grades of rubber. This can be due to a setback in the marketing system for rubber. One usual complaint by smallholders is that because sheet rubber is graded visually, even if they (smallholders) produce higher quality sheets, they are graded lower and are offered low prices by the buyers. Although, there is some truth in this statement, if the grading is correctly carried out by the dealers, then there is an inherent inability on the part of the smallholder to produce high quality 
rubber sheets. Thus, there may be two types of farmers with respect to production quality: those who are able to produce with the required quality standards but are unwilling to do so because of market imperfections and those who are unable to achieve the required level of quality in the production. If we are to study the first group, then it is a study of production choices. If we are concerned with the second group, then it may be the study of resource requirements as these farmers are driven out of the market by some form of deficiency, which may be physical or intellectual. Thus, in order to assess the reasons for lackluster production of high quality rubber sheets, on one hand, we have to assess the factors that influence the production choice. On the other hand, we also have to assess the deficiency in resources to "enter" into the sale of higher grades of RSS. In this study we use an innovative way of looking at all such issues together and develop a Bayesian Belief Network to derive policy prescriptions on improving production of higher grades of sheet rubber. Use of Bayesian networks has several advantages: it enables transparent representation of causal relationships, uses a variety of input data, its ability to represent of uncertainty, and availability of visual decision support tools (Kragt, 2009)

\section{Methods \\ Study area}

Out of all districts under rubber cultivation, Kalutara is a major growing area with 33,598 holdings with an extent of 19,058 ha (Rubber Research Institute, 2010) where, marketing channels are well developed. In the Kalutara district, there are 14 Divisional Secretariat (DS) Divisions. They are: Panadura, Horana, Ingiriya, Bandaragama, Kalutara, Millaniya, Madurawala, Bulathsinghala, Dodangoda, Agalawatta, Palindanuwara, Beruwala, Matugama, and Walallawita (Fig. 2).

\section{Sample selection}

A total sample size of 500 growers is obtained allowing them to be distributed throughout the Kalutara district. This is done through selecting GN divisions from the DS divisions using a multistage cluster sampling technique. There are 14 Divisional Secretariat (DS) divisions and they are divided into 762 Grama Niladhari (GN) Divisions. Targeted GN divisions are selected from the DS divisions using a multistage cluster sampling technique. Number of growers who are selected into the sample from each DS division is determined based on the weighted proportion as;

$$
\text { sample size per DS division }=\frac{\text { No of smallholders in DS division }}{\text { No of smallholders in district }} \times 500
$$




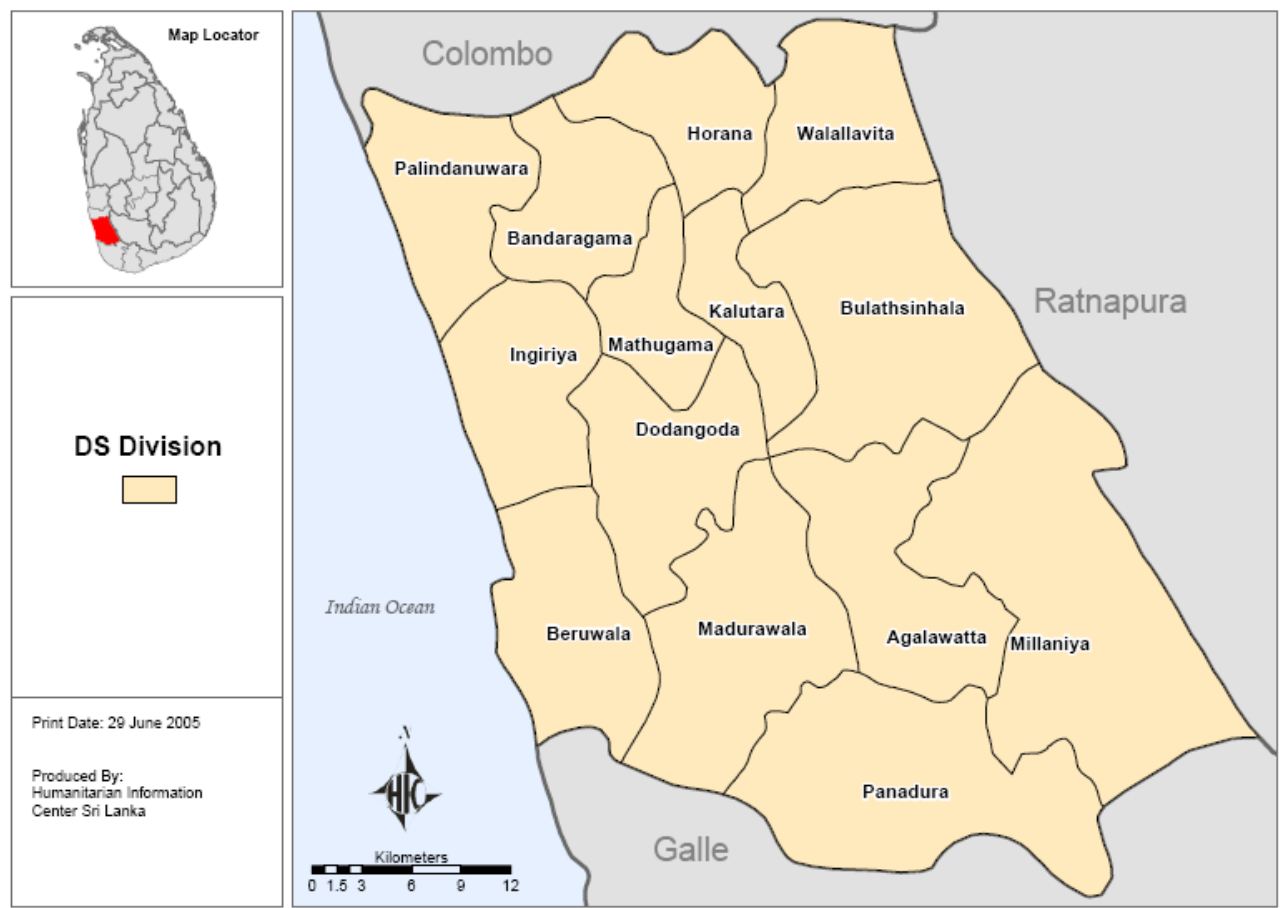

Fig. 2. Administrative map of Kalutara district Source: Humanitarian Information Center (2005)

The number of growers to be selected from each GN division is decided based on the concentration of smallholders in each GN division.

\section{Data collection}

Primary data are used for the study. A pre-tested structured questionnaire and a Participatory Rural Appraisal (PRA) are used to collect data. The questionnaire survey covered different farmers' socioeconomic and demographic characteristics that included: age and gender of the household head, production details, fertilizer application, production and sales, cleanliness of the production process, cost of production, social capital, marketing inefficiency, transaction cost (in selling), resource endowments, perception, knowledge, contact with extension personnel, income and employment, and credit use. Data were collected from May to June, 2012. Selected sample of 500 smallholder farmers were interviewed during the survey with the help of Rubber Development Officers (RDO) employed in the district by the Rubber Development Department (RDD). 


\section{Theoretical framework}

We know that production of RSS1 depend on various factors which may dependent upon numerous other factors. For instance, a grower's decision on sale of latex or RSS may depend on income that either of these production types may generate. But the income may in turn be affected by prices. The prices may in turn be affected by quality, weight and buyers' estimation etc. Hence, probability of occurrence of one event depends on the probability of occurrence of several other events. Such conditional relationships cannot be examined in conventional regression analysis where, most impacts of covariates are measured with 'ceteris paribus' assumption. However, techniques such as Bayesian Belief Networks (BBNs) provide a method to investigate such causal relationships in a simultaneous framework. The BBN is a model for reasoning about uncertainty. It is a directed graph, together with an associated set of probability tables. BBNs are also known as "belief networks", "causal probabilistic networks", "causal nets" and "graphical probability networks". The term Bayesian Networks emphasizes three aspects: The subjective nature of input information, the reliance on Bayes' conditioning as the basis for updating information, distinction between causal and evidential modes of reasoning, which emphasizes Thomas Bayes' ideas (Pearl, 1985). Each node in the BN is related to the other with Bayesian conditional probability. Thus, once the required probabilities are entered into probability table associated with each node, all nodes get updated through conditional probabilities as:

$$
\begin{aligned}
& P\left(X_{1}, X_{2}, \ldots, X_{N}\right) \\
& =\prod_{i=1}^{N} P\left(X_{i} \mid \text { Parents }\left(X_{i}\right)\right)
\end{aligned}
$$

Where, the function Parents (Xi) represents the set of nodes with causal links directed into the node $\mathrm{Xi}$.

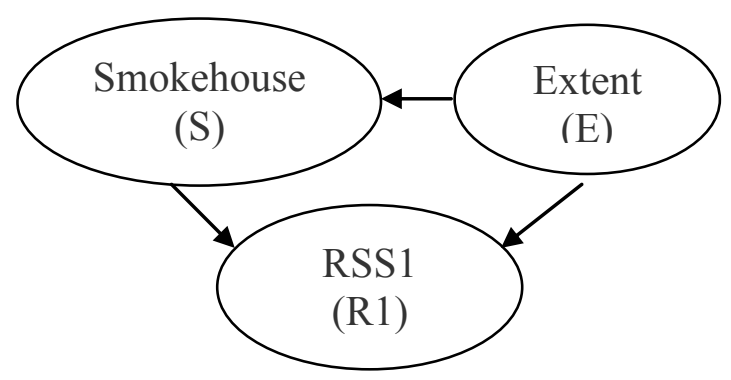

Fig. 3. A typical BBN

For instance, suppose that for simplicity there are two events that lead to production of RSS1: the size of the mature extent of rubber and the availability of a smokehouse (Fig. 3). Also, the size of the mature extent has a direct effect on the availability of a smokehouse assuming that farmers with larger extents will build their own smokehouse. If all three variables have two possible value; True (T) or Falls (F), the joint probability function can be depicted as;

$P(R 1, S, E)=P(R 1 \mid S, E) P(S \mid E) P(E)$ 
$\mathrm{J}$ C Edirisinghe et al.

Where, the names of the variables have been abbreviated to R1 = RSS1 (yes/no), $\mathrm{S}=$ Farmer has a smokehouse (yes/no), and E=Farmers' mature extent is large (yes/no).

The probability that a farmer is a larger farmer (who has a higher mature extent) given that he is producing RSS1 can be obtained by using conditional probability formula and summing over all nuisance variables as;

$$
\begin{aligned}
& P(E=T \mid R 1=T) \\
& =\frac{P(E=T, R 1=T)}{P(R 1=T)} \\
& =\frac{\sum_{S \in\{T, F\}} P(R 1=T, S, E=T)}{\sum_{S, E \in\{T, F\}} P(R 1=T, S, E)}
\end{aligned}
$$

We use the collected primary data quantitatively in a BBN. We aim to use these graphical models that encode probabilistic relationships between variables of interest. The analysis was carried out using NETICA (Version 3.14). It is an easy to use complete program to work with Bayesian networks. It gives the option to enter the relationships with variables as individual probabilities, in the form of equations, or learned from data files. These values or probabilities may be displayed in a number of different ways, including bar graphs and meters. We first model the present situation in a $\mathrm{BBN}$ and then make changes in policy relevant variables and inspect the changes in the production of higher grades of rubber to arrive at the most effective policy.

\section{Uses of BBNs in research}

BBNs are employed in numerous other studies around the world including rubber cultivation. Pike (2004) asses a probabilistic Bayesian network modeling approach to explore the causes of compliance violations in a sample of water treatment systems in Pennsylvania. Chan et al., (2012) reports the development and application of two Bayesian Network models to assist decision making on the environmental flows required to maintain the ecological health of the Daly River (Northern Territory, Australia). Smith et al., (2012) estimate the influence of land management change on weed invasion potential using a Bayesian network. Shenton et al., (2010) describe a BBN model that predicts the effects of nitrogen-fertilizer management strategies in the Tully River catchment (northern Queensland) on the condition of inshore reefs of the Great Barrier Reef. Marcot et al., (2001) developed procedures for using Bayesian belief Network (BBN s) to model habitat and population viability of selected at - risk fish and wildlife species. They found that BBN s were helpful for challenging to articulate what they know about ecological influences on vertebrate species at various levels geographic resolutions, and to knit those influences into ecological causal webs.

Gambelli and Bruschi (2010) develops a model based on a Bayesian network $(\mathrm{BN})$ that is aimed at investigating the factors that affect the exit of a farm 
from the organic sector and to simulate the probability of maintaining an organic scheme for different farm types. Pang and Sun (2011) describes the development of Bayesian networks for evaluating the trade-offs between water utilization for agriculture in Shandong irrigation district and the ecosystems in the Yellow River Estuary. An example from the rubber industry includes modeling the causes for evading from rubber cultivation by Wijesuriya et al. (2003). Wijesena et al., (2006) used Bayesian belief network to identify the factors motivating to smallholders leave dairy industry in Sri Lanka.

\section{Results and Discussion \\ The present situation}

Before collecting data from farmers, we conducted a focus group discussion with Rubber Development Officers (RDOs) in the Kalutara region. Focus groups enable us to identify key variables that affect the farmer choice on production of grade one. We use these variables to construct the BBN we need (Fig. 3). Then we let the household data to automatically generate conditional probabilities in probability table associated with each node.

Because of the low frequency of farmers producing RSS1 we aggregate farmers into groups: those that produce higher grades (RSS3 and above), low grades (RSS4 and 5) those that sell as bulk and those that sell latex. All those variables that are connected directly and indirectly to this decision node are identified through using the information from the focus group. Thus, it assumes that the choice of rubber grade to be produced is affected by the availability of a smokehouse (SMOKE HOUSE), availability of rollers (ROLLERS), extension contact with farmer ('EXTENSION SERVICE'), training received (TRAINING), farmers' view of rubber grading system in the country (GRADING SYSTEM), amount of production (ENOUGH PRODUCTION), cleanliness of latex collection (CLEANLINESS), whether farmers strain latex (STRAIN) and farmer view on their buyers' grading (BUYER GRADING).

The production choice is set to be indirectly associated with the mature extent (MATURE EXTENT), whether farmer adds fertilizer to their fields (FERTILIZER) and the availability of a subsidy (SUBSIDY). The figure inside the nodes represents the frequencies. For example, the node 'SMOKE HOUSE' shows the availability of a smoke house by farmers and only $35.5 \%$ farmers in the sample had a smokehouse while $64.5 \%$ did not have one. According to data, $51.5 \%$ of farmers sell as 'bulk' and a mere 14.5 sell as higher grades (Grade 3 and above). 


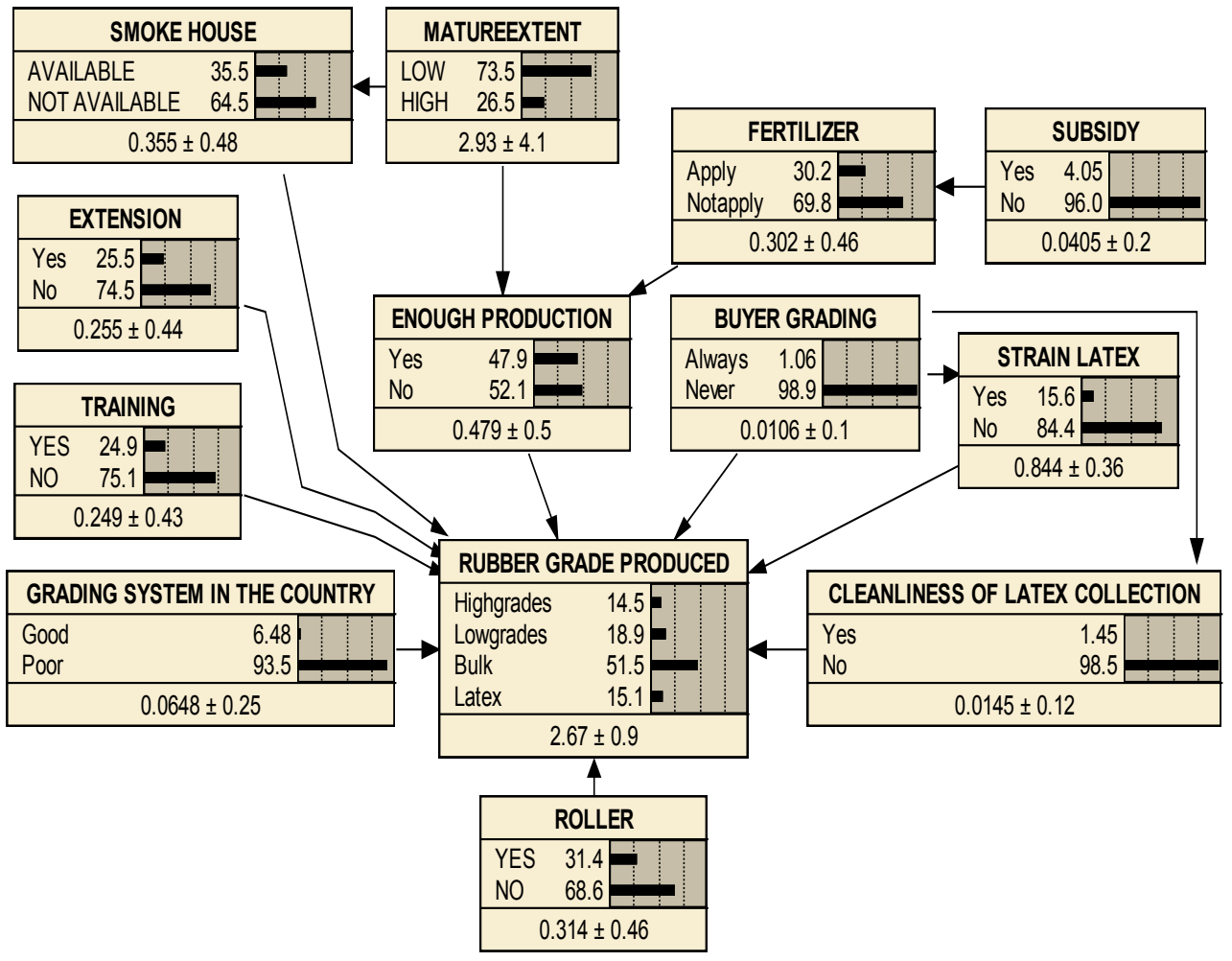

Fig. 3. BBN representing the present situation

\section{Policy simulations}

With the Bayes Net at hand, we make several policy simulations to verify their impact on the increase in production of higher grades of RSS. We first assess the impact of changing levels of physical resources available to farmers. We do this by changing the frequency of node; SMOKE HOUSE and ROLLERS. We make them both $100 \%$. That is, we make all farmers equipped with these two vital resources for sheet production (Fig. 4). We find that this creates a change in the production choice. The production of highest grade increased from $14.5 \%$ to $25 \%$. 


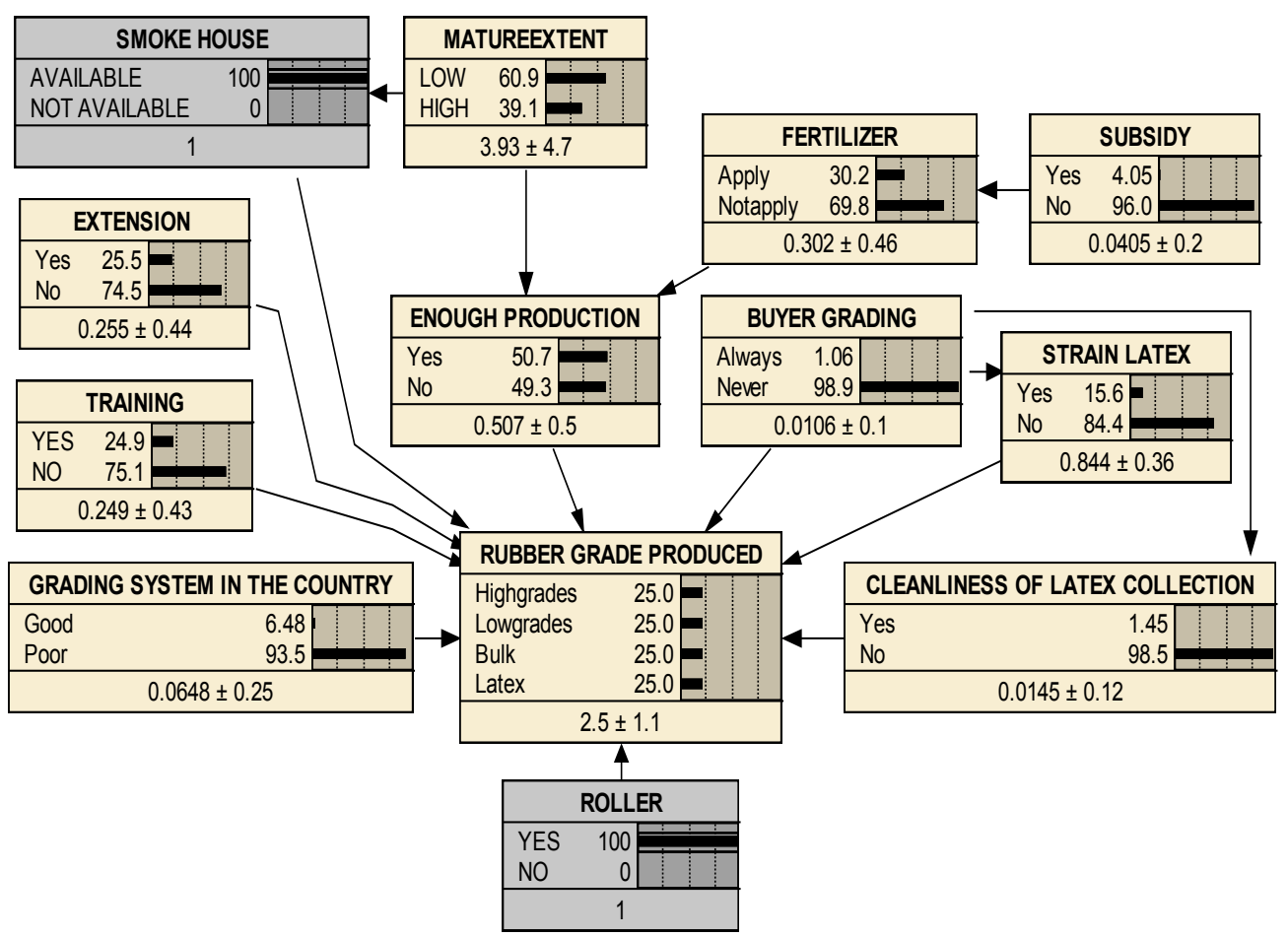

Fig. 4. Simulation of a change in resource availability

Next we investigate the impact of grading by buyers on production of higher grades. We hypothesize that poor grading and purchase in bulk discourage farmers from producing higher grades. We make this node (BUYER GRADING) to represent the situation where buyer always grade rubber sheets correctly. The impact is shown in Figure 5. Results reveal that even if the buyer always grade rubber correctly and pays accordingly to farmers, the increase in production of higher grades is marginal. The increase is from 14.5 to $24.7 \%$. 


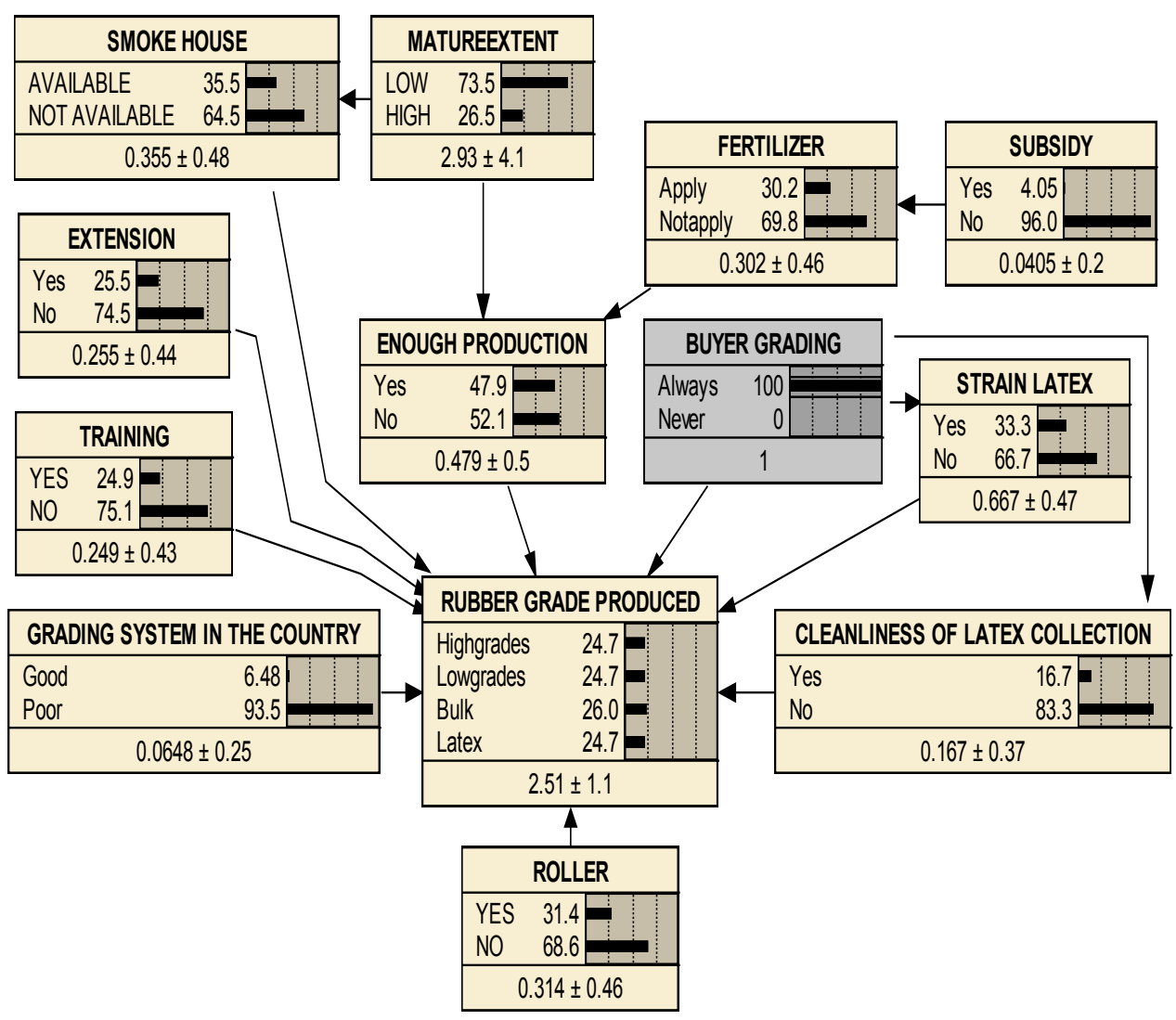

Fig. 5. Impact of buyer grading

Higher grades RSS are the sheets having highest purity and quality. Purity is one major determinant of RSS grading. Straining of latex and cleanliness of latex collection are the highest influencing practices for the higher purity of RSS. Cleanliness of latex collection refers to the frequency of cleaning latex collecting utensils. The effect of highest quality of latex is studied by altering the probability of the nodes,
"STRAIN LATEX" and "CLEANLINESS OF LATEX COLLECTION" (Fig. 6). Increased "STRAIN LATEX" and "CLEANLINESS OF LATEX COLLECTION" have an impact on "RUBBER GRADE PRODUCED"; the "High grades" probability of "RUBBER GRADES PRODUCED", increased from $14.5 \%$ to $24.3 \%$. 


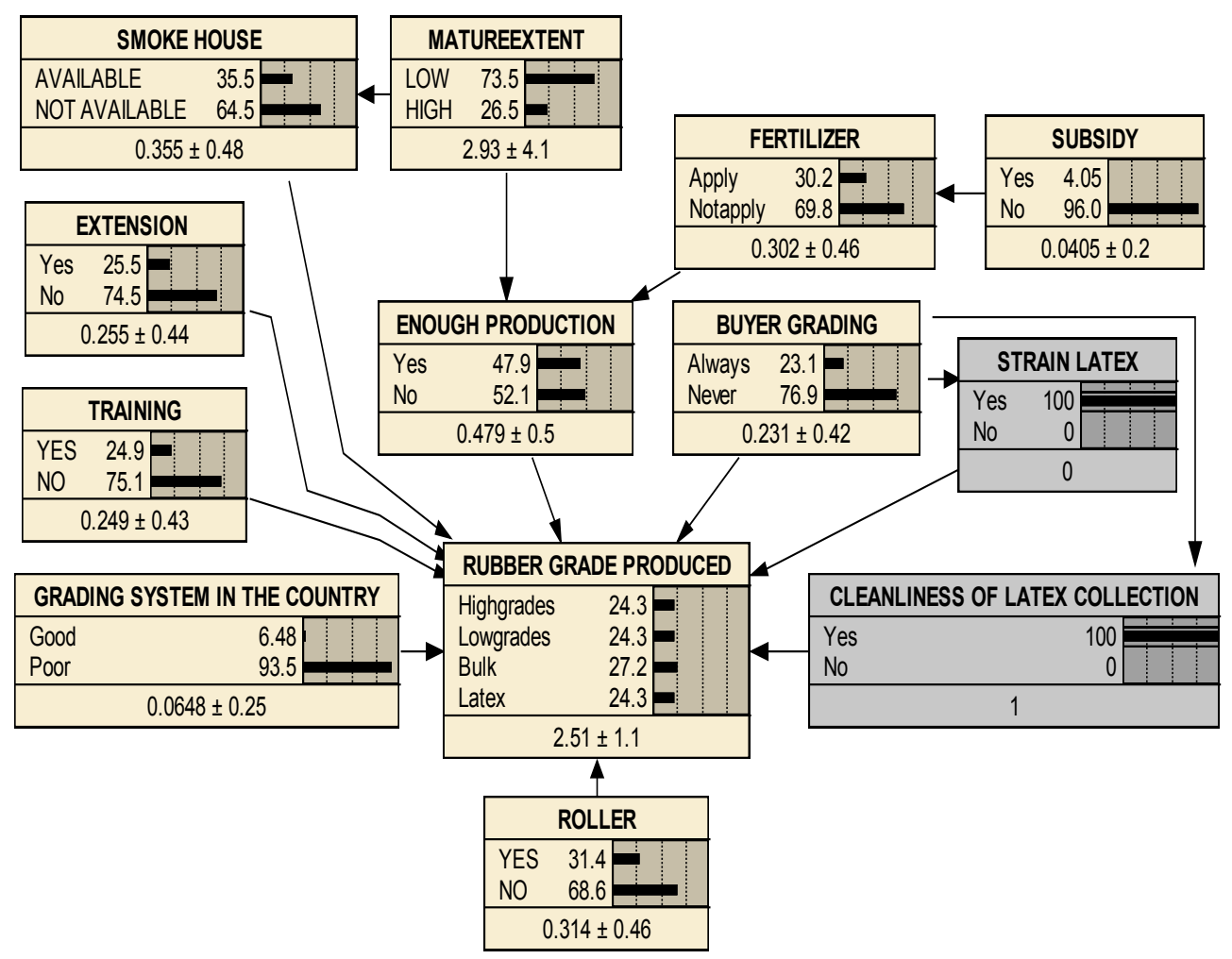

Fig. 6. Effect of clean production

We next turn to review the impact of extension and training on production of higher grades. Training and extension are the core factors which can change smallholders' views and the ways they do things. The effect of training and extension is studied by altering the probability of the nodes, "TRAINING" and "EXTENSION". According to the Figure 7 increased "TRAINING" and "EXTENSION" have a positive impact on "RUBBER GRADE PRODUCED"; the "High grades" probability of "RUBBER GRADES PRODUCED", increased from $14.5 \%$ to $16.9 \%$. 


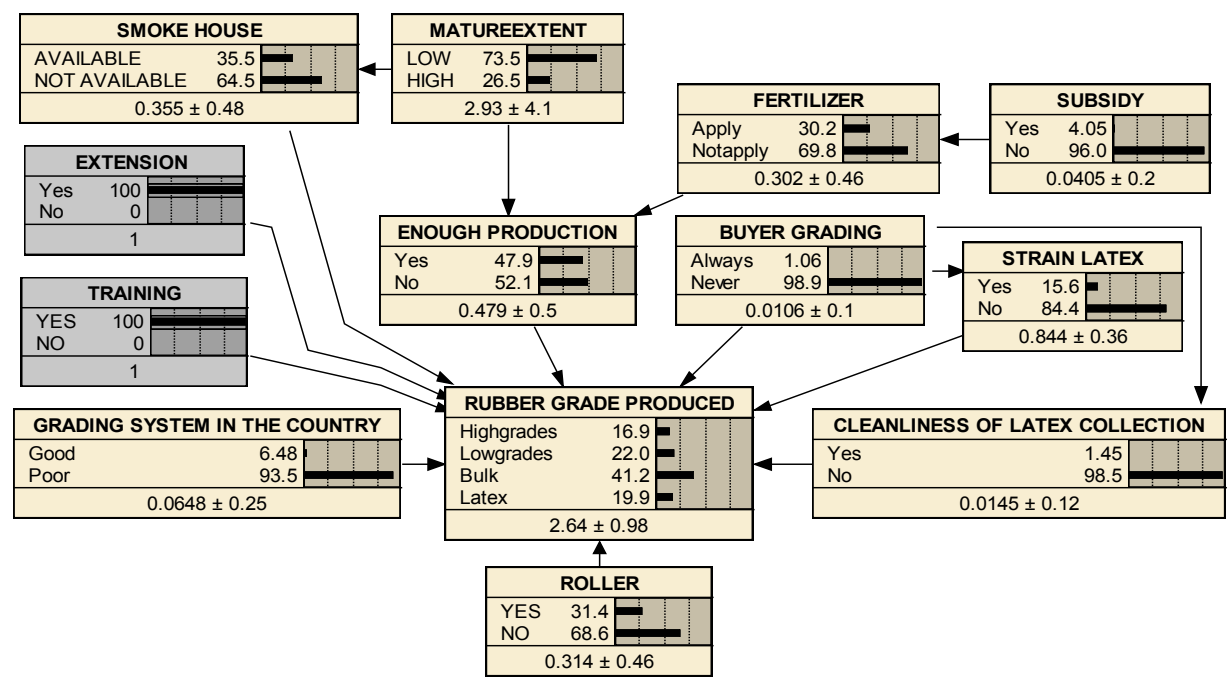

Fig. 7. Impact of training and extension

We summarize below the result of the four policy scenarios we investigated (Table 1).

Table 1. Summary of policy simulation

\begin{tabular}{lcc}
\hline Inferences & $\begin{array}{c}\text { Production of } \\
\text { higher grades }\end{array}$ & $\begin{array}{c}\text { Changes with respect to } \\
\text { current situation }\end{array}$ \\
\hline $\begin{array}{l}\text { 1. Resource Endowments being } \\
\text { "AVAILABLE" and "HIGH" }\end{array}$ & $25 \%$ & $10.5 \%$ \\
$\begin{array}{l}\text { 2. Clean production being "YES" } \\
\text { 3. Training and extension being } \\
\text { "YES" }\end{array}$ & $24.3 \%$ & $9.8 \%$ \\
4. Marketing facilities & $16.9 \%$ & $2.4 \%$ \\
Buyer Grading being "ALWAYS" & $24.7 \%$ & $10.2 \%$ \\
\hline $\begin{array}{l}\text { The highest impact occur with } \\
\text { resource endowment, the provision of } \\
\text { the two vital physical resources for } \\
\text { sheet rubber production: smoke houses } \\
\text { and rollers. Next and almost a similar } \\
\text { impact could be achieved by making }\end{array}$ & $\begin{array}{l}\text { grading. Clean production, is of course } \\
\text { production of higher grades as well. }\end{array}$ \\
\hline
\end{tabular}
impact could be achieved by making 


\section{Conclusion and Policy Implication}

This research attempts to investigate reasons for small farmers' inability to produce higher grades of sheet rubber. The analysis utilizing a Bayesian Belief Network strengthens the importance of physical capital (Rollers, smokehouses and storage space) in production of higher grades of rubber. Additionally, it shows the necessity of having a proper grading system to grade sheet rubber. The lack of a quality management system has eroded the farmers' trust on grading and therefore, is not keen on production in the highest quality. Further, extension service has a role to play. It is evident that improved cleanliness in production would result in producing higher quality sheet rubber. Therefore, farmers should be made aware of clean production, especially, on rolling and smoking procedures.

\section{Acknowledgement}

Authors wish to greatly appreciate the financial support provided by the National Science Foundation under the Research Grant No: RG/2011/SS/01 to carry out this research successfully.

\section{References}

Gambelli, D V, Bruschi (2009). A Bayesian network to predict the probability of organic farms' exit from the sector: A case study from Marche, Italy. Computers and Electronics in Agriculture 71, (1), April 2010, 22-31, ISSN 0168-1699, 10.1016/j.compag. 2009.11.004.

Kragt, M E (2009). A beginners guide to Bayesian network modelling for integrated catchment management. Landscape Logic.

Marcot, B G, Holthausen, R S, Raphael, M $\mathrm{G}$, Rowland, M M and Wisdom, M J (2001). Using Bayesian belief networks to evaluate fish and wildlife population viability under land management alternatives from an environmental impact statement. Forest Ecology and Management 153(1), 29-42.

Pang, P A and Sun, T (2012). Bayesian networks for evaluating trade-offs between water utilization for agriculture and ecosystems. Procedia Environmental Sciences 13, 2374-2382, ISSN 1878-0296, 10.1016/j.proenv. 2012.01.226.

Pearl, J (1985). Bayesian Networks: A Model of Self-Activated Memory for Evidential Reasoning (UCLA Technical Report CSD-850017). Proceedings of the 7th Conference of the Cognitive Science Society, University of California, Irvine, CA. pp. 329-334.

Ministry of Plantation Industries (2012). Statistical Information on Plantation Crops: Available from http://www. plantationindustries.gov.lk/dwnlds/plant ation $/ 2012 \% 20-\% 20$ Statistical $\% 20$ Information $\% 20$ on $\% 20$ Plantation $\% 20 \mathrm{Cr}$ ops.pdf (Accessed 18 August 2014).

Rubber Research Institute (2010). Key indicators: Rubber Available from: http://www.rrisl.lk/sub_pags/statistics.ht ml (Accessed 15 June 2012)

Shenton, W, Hart, B T and Brodie, J (2010). A Bayesian network model linking nutrient management actions in the Tully catchment (Northern Queensland) with Great Barrier Reef condition. Marine and Freshwater Research 61(5), 587595.

Smith. C, van Klinken, R D, Seabrook, L and McAlpine, C (2012). Estimating the 
influence of land management change on weed invasion potential using expert knowledge. Diversity and Distributions 18, 818-831. doi: $10.1111 / \mathrm{j} .1472-$ 4642.2011.00871.x

Wijesena, K A $\mathrm{K}$ Edirisinghe, $\mathrm{J}$ and Auwardt, D M (2006). Why do smallholders leave the dairy industry in Sri Lanka? In: Proceedings of the 6th Agricultural Research Symposium, Makandura: Faculty of Agriculture and Plantation Management, Wayamba University of Sri Lanka. pp 108-111.

Wijesuriya, W (2008). An approach towards sustainable development and economics of the smallholder rubber sector in the Moneragala district, Final Report, NSF.

Wijesuriya, Wasana, Thattil, $\mathrm{R} \mathrm{O}$ and Herath, H M L K (2003). Quantifying causal maps in participatory studies conducted in the smallholder rubber sector using Baysian Network (BN) approach. Sri Lankan Journal of Applied Statistics 4, 27-36.

Humanitarian Information Center (2005).

Available from http://www.humani tarianinfo.org/ srilanka/catalogue/

(Accessed 12 March 2012).

Address for correspondence: Dr Jagath C Edirisinghe, Dept. of Agribusiness Management, Faculty of Agriculture and Plantation Management, Wayamba University of Sri Lanka, Makandura, Gonawila (NWP).

e-mail:jagathed@yahoo.com 